\title{
Salud pública e inestabilidad política en Venezuela durante los gobiernos de Guzmán Blanco, 1870-1888
}

\section{Cristian Camacho}

Universidad de los Andes Mérida, Venezuela

En este artículo se analiza cómo durante el guzmancismo, los ciclos epidémicos ocasionaban en el gobierno un ambiente de desconfianza y tensión política, porque de manera equivocada se pensaba que eran empleados por algunos opositores para incidir en el cierre de los puertos, paralizar el intercambio, cortar el flujo de recursos económicos provenientes del comercio exterior y obtener así beneficios políticos. El gobierno se movilizaba para evitar rumores y reprimir cualquier tipo de acción política al respecto, con el fin de impedir que la oposición diera uso político a los ciclos epidémicos; también ejecutaba con eficiencia una política de información que, desde los Consulados, le permitía estar al corriente acerca del movimiento de los barcos y su situación sanitaria interna; además se desarrolló un conjunto de previsiones nacionales e internacionales altamente benéficas en el control y manejo de los períodos epidémicos.

PAlabras ClaVE: Guzmán Blanco, inestabilidad política, salud pública, Historia, control sanitario.

In this paper, we analyze how during Guzmán Blanco governmental periods epidemic cycles generated a sense of distrust and political instability. The misinterpretation form governmental authorities lead to think that oppositionists promoted the closure of ports, a halt on exchange and limitations to the access to economic resources coming from foreign trade with the purpose of obtain political benefits. To avoid oppositionists politically use epidemics cycles, governmental action were addressed to prevent rumors and to put down any political action related to this matter. Gúzman government also efficiently carried out an information policy from consular offices aimed to take advantage from up-to-date information with respect to vessels movements and their internal health situation. Moreover, a set of highly effective national and international preventative measure were adopted in order to control and manage epidemic cycles.

Keywords: Guzmán Blanco. Political Instability. Public Health History. Sanitary Control.

\section{Introducción}

Los países independientes de Hispanoamérica, al liberarse de la subordinación absoluta de España, pronto confrontaron el problema de su estabilidad interna como una situación de primer orden. El desarrollo del poten- 
cial económico y la influencia política de EUA, fueron factores contribuyentes para que disminuyera la amenaza de un enemigo extracontinental. En cambio, internamente, la agudización de las desigualdades como consecuencia de la nueva distribución del poder, ahondó la diferencia de los grupos gobernantes con quienes se sentían desplazados de las oportunidades de mando y enriquecimiento, caudillos militares y civiles que eran una continua amenaza para la estabilidad y seguridad nacional.

Esa era una de las características de Venezuela en el siglo XIX, particularmente durante el guzmancismo. Esto fue perfectamente conocido por ese gobernante, quien, consciente de las limitaciones de su régimen, creó una serie de alternativas políticas, legales y financieras utilizadas como instrumento para garantizar la seguridad interna. Entre esas alternativas figuraron los empréstitos internacionales, períodos bienales de gobierno y una normativa legal a la medida, todo lo cual permitió superar algunas amenazas cernidas sobre el régimen.

Desde luego, las amenazas internas no eran tan sólo políticas, económicas o militares; también existían aquellas directamente relacionadas con accidentes y calamidades en el área de la salud pública, específicamente en el grupo de enfermedades infecciosas y parasitarias que, por sus efectos sociales y económicos (epidemias), representaron siempre una amenaza de importancia para los gobiernos, cuando eran utilizadas por la oposición para esparcir rumores y debilitar las bases del poder.

Naturalmente, los percances epidémicos magnificaban el conflicto, el cual se extendía motivado también por limitaciones institucionales, promesas incumplidas y reformas sociales postergadas. Así ocurrió con la oferta de "hacer imperar la ley" y el ofrecimiento de libertad e igualdad para "los de abajo". Al no satisfacer las expectativas se generaban trastornos que prendían en una sociedad estructuralmente débil. Los opositores políticos explotaban la situación y las exiguas capacidades del gobierno en el manejo de la crisis, para avivar la llama del conflicto y obstaculizar la gobernabilidad. El pronóstico para los gobernantes era la acentuación de la inestabilidad y el riesgo de ser expulsados del poder.

\section{Control de consecuencias económicas producidas por epidemias y enfermedades}

El comportamiento de la economía venezolana durante el guzmancismo, estuvo condicionado por los requerimientos del mercado mundial, 
monopolizado por las economías de Inglaterra, Francia, Alemania y EUA. Esos requerimientos, principalmente de bienes agropecuarios, crearon condiciones favorables para el incremento del comercio de exportación de materias primas. Se produjo, entonces, el crecimiento relativo de la actividad agrícola venezolana, pero sin un desarrollo paralelo de la pequeña y mediana producción industrial y artesanal, razón por la cual se recurrió a la importación de productos elaborados, anulándose así cualquier posibilidad de progreso en este sector. Por consiguiente, el mercado interno se mantuvo estrecho y reducido, consolidándose el predominio del latifundio y la preponderancia del comercio exterior. Naturalmente, a estos inconvenientes deben agregarse los problemas creados por la dificultad técnica de las comunicaciones que obstaculizaba la existencia de un mercado nacional; también la ausencia de un sistema educativo que, entre otras cosas, se ocupara de especializar la mano de obra y de abrirle posibilidades tecnológicas al país, para transformar la hacienda como unidad de producción y aportar recursos que permitieran mejorar la infraestructura operativa del país: caminos, carreteras, puentes, canales, puertos, edificios públicos, etc.

La economía era extremadamente vulnerable, pues dependía del comercio exterior casi en su totalidad, conforme lo revela el cuadro 1 . De acuerdo con esos datos, el impuesto al comercio importador entre 1870 y 1880, produjo un ingreso de casi 186 millones de bolívares, cantidad que representó poco más del $76 \%$ del ingreso total a la nación. En cambio, por concepto del comercio interno de salinas y estampillas en el mismo lapso, la recaudación llegó a 7.394.930 bolívares, suma correspondiente al 3.1\% del ingreso total.

Ese hecho de singular importancia otorgaba a los puertos nacionales, principalmente a los de la región centro-norte-costera, una importancia estratégica relevante, pues el comercio exterior era vital para el soporte del aparato gubernamental. Es así cómo desde tiempos coloniales los puertos tuvieron una eficaz y excepcional asistencia económica, política y militar, la cual se incrementó durante el guzmancismo debido a la profundización alcanzada por la dependencia de este comercio.

Consciente de esta realidad, el guzmancismo ejecutó importantes inversiones en la construcción de nuevos puertos y en el mantenimiento de los existentes. Además, mediante decreto de 9 de diciembre de 1870, creó la Compañía de Crédito para recaudar los ingresos aduaneros obtenidos en 
el puerto de La Guaira. ${ }^{1}$ Tal como se aprecia en el cuadro 2, las inversiones portuarias fueron superiores a los gastos en defensa. Esa conducta se debió a una mayor valoración política, militar y sanitaria de aquellos factores que, como los puertos, le garantizaban al gobierno mantener el presupuesto fiscal a expensas del tributo al comercio exterior. Como es de suponer, la seguridad portuaria no sólo era necesaria para mantener el flujo de los ingresos fiscales, sino también necesaria para garantizar la estabilidad del régimen, ya que el cierre de un puerto clave como La Guaira o Puerto Cabello, era políticamente catastrófico para el gobierno porque implicaba la suspensión del cobro de impuestos debido a que los barcos no podían atracar, mucho menos cargar o descargar mercancías, por el temor al contagio y porque lo prohibían las respectivas leyes de sus países.

\section{CUADRO 1}

\section{COMERCIO EXTERIOR E INGRESOS FISCALES DE VENEZUELA,} 1870-1880 (en bolívares)

\begin{tabular}{cccccr}
$\begin{array}{c}\text { Años } \\
\text { Fiscales }\end{array}$ & $\begin{array}{c}\text { Derechos } \\
\text { de importación }\end{array}$ & $\%$ & $\begin{array}{c}\text { Salinas y } \\
\text { Estampillas }\end{array}$ & $\%$ & Totales \\
\hline $1870-1871$ & 17.171 .660 & 90.8 & 271.267 & 1.6 & 18.900 .000 \\
$1871-1872$ & 11.938 .451 & 89.7 & - & - & 13.297 .513 \\
$1872-1873$ & 17.892 .006 & 75.5 & 205.935 & 1.0 & 23.676 .642 \\
$1873-1874$ & 22.829 .288 & 79.5 & 628.308 & 2.1 & 28.685 .117 \\
$1874-1875$ & 19.531 .747 & 81.0 & 1.321 .054 & 5.4 & 24.181 .747 \\
$1875-1876$ & 26.058 .714 & 79.9 & 1.192 .190 & 3.6 & 32.626 .049 \\
$1876-1877$ & 19.325 .222 & 73.6 & 1.406 .402 & 5.3 & 26.256 .829 \\
$1877-1878$ & 13.673 .891 & 57.4 & 565.000 & 2.3 & 23.834 .000 \\
$1878-1879$ & 15.746 .765 & 68.5 & 512.482 & 2.2 & 23.000 .482 \\
$1879-1880$ & 21.825 .371 & 75.4 & 1.292 .292 & 4.4 & 28.912 .869 \\
\hline Totales: & 185.993 .115 & 76.4 & 7.394 .930 & 3.1 & 243.371 .248
\end{tabular}

Fuente: Veloz, Ramón: Economía y finanzas de Venezuela desde 1830 hasta 1944, Impresores Unidos, Caracas, 1945, pág. 153 y ss. Salinas y Estampillas: Izard, Miguel: Series estadísticas para la historia de Venezuela, Universidad de Los Andes, CDCH, Facultad de Humanidades, Mérida, Venezuela, pág. 171. Totales: D’Ascoli, Carlos: Esquema Histórico-económico de Venezuela (del mito de El Dorado a la economía del café), Ediciones del Banco Central de Venezuela, Caracas, 1970, pág. 336.

1 Polanco Alcántara, Tomás: Guzmán Blanco, tragedia en seis partes y un epílogo, Academia Nacional de la Historia Grijalbo, Caracas, 1992, págs. 361-362. También González Deluca, María Elena: Negocios y política en tiempos de Guzmán Blanco, Universidad Central de Venezuela, Caracas, 1991, págs. 74 y ss. 
CUAdRO 2

INVERSIONES EN PUERTOS Y DEFENSA, 1870-1888

(en miles de bolívares y \%)

\begin{tabular}{ccccc} 
Años & $\begin{array}{c}\text { Puertos } \\
\text { por partida }\end{array}$ & $\begin{array}{c}\text { Total egresos } \\
\text { Nacional }\end{array}$ & $\begin{array}{c}\text { En Defensa } \\
\text { por partida }\end{array}$ & Total egresos \\
\hline $1870-77$ & 912.000 & 4.09 & 126.000 & 0.56 \\
$1877-78$ & 3.000 & 0.12 & 14.000 & 0.58 \\
$1878-84$ & 144.000 & 0.91 & 130.000 & 0.82 \\
$1884-86$ & 129.000 & 2.27 & 40.000 & 0.70 \\
$1886-88$ & 585.000 & 8.98 & 72.000 & 1.10 \\
\hline Totales: & 1.773 .000 & 3.37 & 382.000 & 0.72
\end{tabular}

Fuente: Izard, Miguel, Series estadísticas..., págs. 174-175.

Un aspecto de la seguridad se relacionaba con el control de consecuencias económicas producidas por epidemias y enfermedades. El examen de esos padecimientos se percibía como un problema de seguridad nacional y frecuentemente era ubicado dentro de áreas prioritarias, por considerarse más importante que algunas rebeliones y alzamientos. Cuando se presentaba alguna circunstancia de esta naturaleza, se originaba un clima de desconfianza y tensión política, como el ocurrido en la ciudad de La Guaira a finales de 1881 .

En el mes de diciembre de ese año ocurrieron allí algunos casos de fiebre amarilla que causaron la muerte de varias personas. Esa circunstancia, sin llegar a ser epidémica, causó gran revuelo en la ciudad y en la tripulación de los barcos comerciales atracados en el puerto o aproximándose a él. Inmediatamente las autoridades portuarias procedieron a otorgar "patente sucia" a los barcos, los cuales automáticamente se retiraron, algunos sin cargar o descargar la mercancía. Esto originó alarma natural en las autoridades por el temor a no recaudar los impuestos respectivos:

... los vapores que son los que hacen el comercio se retirarían o no vendrían y se acaba la recaudación de esta aduana... ${ }^{2}$

2 Archivo General de la Nación (en adelante: AGN), Venezuela, Época Republicana, Sección Secretaría de Interior y Justicia, 1880, t. MXXVIII, f. 22 vto. 
Hechos como este suscitaban verdadero pánico en el gobierno, lo cual era natural porque el normal funcionamiento del puerto de La Guaira era vital para Caracas y el gobierno. Esa preocupación era mayor al saberse que la capacidad de otros puertos era insuficiente y la posibilidad de improvisar unos nuevos era nula. Además, no existía una red suficiente de caminos y los existentes no eran confiables para el resguardo de impuestos y mercancías.

El control de la situación implicaba medidas de tipo sanitario. Así, cuando en 1884 se desató una epidemia de cólera en gran parte del continente europeo, a la vez que de fiebre amarilla en Venezuela, el gobierno tuvo especial cuidado en implementar medidas económicas y sanitarias para controlar y evitar posibles consecuencias económicas y sanitarias. Para ello el gobierno recomendaba a las autoridades portuarias el estricto cumplimiento de las leyes sobre la materia, a fin de garantizar condiciones sanitarias convenientes para la tripulación de los barcos que arribaban a puertos nacionales. De esa manera se evitaba que los buques mercantes se vieran impedidos para realizar las operaciones comerciales de importación y exportación, clave para la estabilidad política del régimen.

\section{Control de epidemias y enfermedades. Acciones políticas}

Históricamente, las epidemias y enfermedades han sido un factor influyente en los acontecimientos políticos de cualquier sociedad. Son bastante conocidos los efectos de pestes y epidemias sobre las estructuras políticas de Europa entre los siglos XIV y XVIII. Durante ese periodo la población, la economía y la política europeas se vieron muy afectados por esos flagelos, los cuales, junto a otros factores como heladas, guerras, hambrunas, etc., provocaron situaciones de inestabilidad en varias naciones debido a los daños ocasionados a la actividad económica y a la productividad. En ciertas oportunidades, las enfermedades y epidemias eran aprovechadas para responsabilizar al adversario y obtener beneficios políticos. Esto obligó a que los gobiernos establecieran controles, algunos de los cuales comenzaron a desarrollarse en Venezuela durante la colonia cuando los españoles necesitaron proteger sus puertos y ciudades para defender a los vecinos y a la economía.

La república posterior a 1830 incrementó el control político sobre todos los campos de la salud pública. Se trataba de acciones que muchas 
veces invadían el criterio profesional de los médicos para ejercer. Algunos de ellos protestaron por la existencia de ese control político. En 1858 el médico Marcos Aurelio Rojas protestaba contra la "absurda organización" impuesta por los intereses gubernamentales a la actividad médica. Agregaba que la política debía reducir el control sobre tales procedimientos para que las instituciones y la actividad médico-asistencial estuvieran alejadas de la influencia partidista y pudieran cumplir su función sin interferencias al rigor profesional. ${ }^{3}$ Esto fue una consecuencia del profundo centralismo establecido por el Poder Ejecutivo sobre casi toda la estructura del Estado. El control aumentaba y se hacía necesario en las instituciones y actividades que para el Ejecutivo eran de importancia, como el Parlamento, la Hacienda pública, el Ejército y la salud pública. ${ }^{4}$

La función contralora del gobierno sobre las actividades asistenciales y de salud, se debía también a la necesidad de mantener control sobre aquellos adversarios del régimen, de los cuales el gobierno sospechaba que eran capaces de aprovechar la contingencia para obtener beneficios políticos. ${ }^{5}$ De manera bien ocasional, ese estilo de oposición ocurría en Hispanoamérica. Es conocido el hecho sucedido en Guatemala (1837), cuando enemigos del gobierno de la Federación Centroamericana, presidido por el general Mariano Gálvez, usaron la circunstancia epidémica (cólera), para propagar la mentira de que ese gobierno había ordenado contaminar las aguas con un veneno causante de la enfermedad. La noticia provocó la animosidad de la población contra las autoridades y no se permitió que los médicos examinaran a los enfermos por temor a "nuevas represalias" gubernamentales. ${ }^{6}$

3 Ver Archivo de la Academia Nacional de la Historia. Rojas, Marco Aurelio: Cartas a Sofía (manuscrito), cap. III, págs. 61-62.

4 Desde luego, esto no significó que se diera prioridad absoluta a la salud pública. La magnitud de la asistencia estatal a los programas sanitarios dependía de la circunstancia histórica vivida por el país y también por la ubicación geográfica de esos programas. No era lo mismo auspiciar el funcionamiento de esas instituciones en tiempos de guerra que de paz; ni tampoco se daba igual prioridad a las instituciones centrales y a las que no lo eran. Las actividades médico-sanitarias fueron orientadas de acuerdo a este enfoque y su realización tuvo más efecto en las zonas centrales de Venezuela.

5 Es oportuno señalar que las crisis políticas de aquella época no eran la consecuencia absoluta de epidemias y enfermedades, y aunque muchas veces generaban el conflicto, la mayoría de ellas actuaba como elemento complementario al lado del desorden político, las crisis fiscales y el desequilibrio económico. En todo caso, la utilización política por parte de la oposición de elementos relacionados con la salud pública, agudizaba la centralización y control de las actividades médico-asistenciales y de sus instituciones.

6 Figueroa, Horacio: "El cólera morbus, pretexto para la Revolución y la sátira"; en Revista de la Sociedad Venezolana de Historia de la Medicina, N. ${ }^{\circ}$ 24, vol. X, Caracas, enero-diciembre de 1962, pág. 162. 
En Venezuela también ocurrían casos relativamente parecidos. En 1855, algunas regiones de Venezuela, principalmente La Guaira y Caracas, fueron atacadas por el cólera. La propagación de la enfermedad por casi todo el país fue aprovechada por los enemigos de José Gregorio Monagas, para divulgar rumores antigubernamentales. Esto produjo la natural reacción del gobierno y el 28 de agosto el ministro de Relaciones Interiores envió una circular a los gobernadores donde se condenaba esa conducta y los prevenía a permanecer vigilantes:

...para desvanecer las voces alarmantes que se propagan acerca de la epidemia aparecida (...) y precaver y reprimir las consecuencias políticas a que puedan dar origen una idea falsa del gobierno y de la capital.?

El mismo caso de fiebre amarilla ocurrido en La Guaira en 1881, sirve para demostrar cómo los gobiernos guzmancistas seguían manteniendo una conducta de sospecha y recelo cuando se presentaban los brotes. Al respecto, la Junta Médica examinó los casos y sesionó los días 13 y 14 de diciembre: discutieron el caso de dos ciudadanos árabes víctimas de fiebre amarilla a juicio de unos, y de insolación según otros. No obstante, la Junta acordó acciones en caso de sobrevenir la muerte de alguno. Se aprobó desinfectar el edificio donde estaban recluidos los enfermos y enterrar el cadáver fuera del poblado. Asimismo se acordó invitar a otros médicos a expresar su opinión y evitar así una epidemia, cuyas sospechas comenzaban a inquietar a la población y al gobierno. ${ }^{8}$

Uno de los contagiados falleció el día 14 del mismo mes de diciembre y la Junta procedió conforme a lo acordado, sin embargo, prosiguió la polémica en torno al caso. El resultado fue que no hubo diagnóstico oficial por parte del organismo, aún cuando los médicos ratificaron sus opiniones. No obstante, apoyándose en este pronunciamiento, el presidente de la Junta procedió a declarar a la fiebre amarilla como causante de la muerte. Inmediatamente se acordó expedir las respectivas patentes de navegación, anotando allí el caso de fiebre amarilla presentado en La Guaira. ${ }^{9}$

7 "Circular del Ministerio de Relaciones Interiores" en Alegría, Ceferino: Contribución al estudio de la salud en la Cuatricentenaria ciudad de Caracas, mimeo, Publicaciones de la Sociedad Venezolana de Salud Pública, Caracas, 1966, pág. 145.

8 AGN, Venezuela, Época Republicana, Sección Secretaría de Interior y Justicia, 1880, t. MXXVIII, f. 6 y ss.

9 Ibídem, fs. 8-9. 
La actitud asumida por el presidente de la Junta y otros médicos fue equivocadamente interpretada por un funcionario gubernamental de apellido Carabaño, quien calificó la decisión profesional como un acto de conspiración política y hostilidad contra el gobierno. El 14 de diciembre envió un telegrama al ministro de Relaciones Interiores donde afirmaba que:

...con el objeto de producir el alarma e impedir la llegada de buques a este puerto, los conspiradores de aquí están difundiendo la noticia de que existe la fiebre amarilla en esta ciudad con el pretexto de la muerte de un árabe. ${ }^{10}$

El señor Carabaño tenía la convicción de que se trataba de una conspiración política y en el mismo telegrama le proponía al ministro acciones policiales para reprimir las pretensiones de los impulsores. Sin embargo, la suspicacia de una conspiración política no era exclusiva de Carabaño. También sospechaba un funcionario del Ministerio de Hacienda en el puerto de La Guaira, J.B. Arismendi, quien el 14 del mismo mes de diciembre, telegrafió al ministro comunicándole oficialmente acerca de la muerte y exponiéndole las diversas opiniones médicas en torno al caso. Agregaba que las noticias sobre las víctimas de fiebre amarilla se estaban divulgando intencionalmente y temía la posibilidad de un plan político para derrocar el gobierno. ${ }^{11}$

Pese a todos los temores, el Gobierno y el fisco no corrieron mayores riesgos ya que, gracias a la cuarentena y el aislamiento, la enfermedad no se propagó. El primero tuvo tiempo para investigar más detenidamente y decidió entrevistarse con los médicos, por lo que el 15 de diciembre el encargado de la presidencia convocó a los doctores Izaguirre y Palacios para que se presentaran al Ministerio de Relaciones Interiores. ${ }^{12}$ De esa entrevista resultó clara la opinión del Gobierno de que los médicos no eran conspiradores y de que su diagnóstico obedeció exclusivamente a razones profesionales. Para verificar más la situación, el ministro comisionó a La Guaira al general Quevedo, quien desde allí telegrafió al ministro Vicente Amengual lo siguiente:

Yo aseguro a usted que [los médicos] no son conspiradores, este es un asunto de localidad..$^{13}$

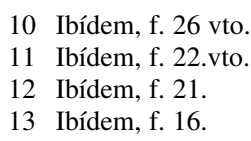


De esa manera el problema quedó resuelto, pues se verificó la sana intención de los médicos y el firme propósito del gobierno de controlar cualquier epidemia u otra contingencia de tipo sanitario que pudiera trastornar la situación política nacional, a través de acciones preventivas en lo político.

\section{Control de epidemias y enfermedades. Acciones sanitarias}

El ámbito de los controles establecidos iba más allá de lo político y económico. También existía con cierta regularidad un control sanitario sobre los factores epidemiológicos, apoyados en previsiones nacionales e internacionales, que en muchos casos funcionaba con increíble eficacia, lo cual contrastaba con la ineficacia administrativa en otras áreas de la gestión gubernamental. Hay que tener en cuenta que esas previsiones eran establecidas por los gobiernos de cada nación sin que existiera la supervisión de un organismo internacional especializado. Los gobiernos guzmancistas fueron muy celosos y eficaces en el cumplimiento de las medidas preventivas. A instancias del Gobierno nacional, eran objeto de un estricto cumplimiento en cada uno de los Consulados que Venezuela tenía en distintos lugares del mundo. La acción preventiva funcionaba coordinadamente con las medidas sanitarias tomadas en el país, y, específicamente, en las regiones vinculadas a los puertos nacionales. La preocupación por mantener esa eficiencia se debía al propósito de garantizar los beneficios que reportaba al comercio exterior, el cual, como se ha dicho, proporcionaba más del 96 por ciento del ingreso nacional.

\section{Establecimiento de previsiones}

Las previsiones sanitarias adoptadas y relacionadas con el comercio exterior, eran de dos tipos: las internacionales, que debían cumplirse estrictamente en los Consulados venezolanos; y las nacionales, que se ejecutaban en lugares localizados del país (ciudades portuarias o muy vinculadas con los puertos nacionales).

\section{Previsiones en los Consulados venezolanos}

El propósito de estas era impedir al máximo que desde países extranjeros pudiesen llegar enfermedades y epidemias, principalmente a los puer- 
tos nacionales. Venezuela mantenía relaciones diplomáticas y comerciales con los países más importantes de Europa y América, lugares que aún seguían padeciendo enfermedades transmisibles como consecuencia del contacto de la población nativa con tripulantes y pasajeros de buques mercantes. Por tanto, la magnitud del comercio internacional exigía un meticuloso control sanitario de las embarcaciones, tripulaciones y pasajeros que llegaban al país o salían de él. Esta vigilancia también la cumplían los cónsules venezolanos en los puertos donde hacían escala los barcos con destino a Venezuela. Todo este procedimiento se aplicaba según la legislación venezolana.

No obstante que gran parte de la legislación al respecto tenía raíces coloniales, el guzmancismo adoptó una serie de medidas que orientaban la acción consular en esta materia. En diciembre de 1873, el Ministerio de Relaciones Exteriores, ante epidemias ocurridas en países europeos y americanos, actualizó una Circular del 28 de agosto de $1866,{ }^{14}$ la cual recogía una serie de recomendaciones para los agentes venezolanos en el extranjero. El primer punto contenido en el documento exhorta a los cónsules a observar y cumplir, con seriedad y constancia, la política de resguardo sanitario de nuestros puertos. Este era un punto importante porque alertaba a los representantes consulares a mantenerse en alerta permanente y no esperar los brotes epidémicos para hacerlo. Agregaba la Circular que en los lugares afectados donde se expedía "patente limpia" de navegación para buques destinados a Venezuela, los cónsules debían expresar en los documentos "su propio juicio acerca de la exactitud de la certificación"; pero al mismo tiempo resumir brevemente en las cartas "el estado de la enfermedad el día de la partida del buque y en los anteriores inmediatos". En la misma obligación estaban para los casos de embarcaciones menores a doscientas toneladas. ${ }^{15}$

Como se observa, el Ministerio de Relaciones Exteriores era muy celoso y no confiaba en el juicio emitido por un extranjero. Esta suspicacia no era un capricho burocrático sino que obedecía a que, con frecuencia, las patentes eran adulteradas o sus datos no eran precisos, unas veces por negligencia de los empleados extranjeros y otras por conveniencia de las autoridades del lugar, las cuales, por aligerar el trámite, liberarse de una

14 "Circular a los Presidentes de los Estados sobre prevenciones referentes a la presentación del cólera en algunos lugares de Europa; Caracas, 28 de agosto de 1866"; en Gaceta Oficial, N. ${ }^{\circ} 158$, 2 de diciembre de 1873.

15 Ídem. 
embarcación contaminada o no abortar la carga de los barcos, procedían a tergiversar la información respectiva. Por esas razones, el cónsul estaba en la obligación de revisar cuidadosamente la documentación en sus manos para evitar la llegada de barcos contaminados a puertos venezolanos.

Más adelante se establecían las líneas a seguir, si se trataba de buques destinados a Venezuela provenientes de lugares distintos a la residencia del cónsul. En este caso, se procedía como lo indicado anteriormente, pero era necesario revisar las patentes de navegación expedidas en otros puertos para verificar su limpieza. Si esto no era posible, el cónsul quedaba autorizado para no dar curso a la documentación, necesaria para el tránsito. Igualmente se ordenaba que cualquier información debía comunicarse con urgencia, directamente al Ministerio de Relaciones Exteriores. Este último punto permitía conocer con anticipación el estado sanitario de los barcos para estar alerta frente a las naves que, sin el respectivo permiso y contraviniendo las leyes nacionales, procedían a no reconocer la autoridad del cónsul respectivo. En estos casos, una vez el barco en territorio venezolano, se procedía a verificar su estado sanitario y aplicar la acción policial necesaria.

La función contralora de los cónsules no era exclusiva para los barcos con destino a Venezuela. En el documento citado se señala:

...que aún cuando no sea ocasión para despacharse bajeles mercantes para los puertos nacionales, los cónsules deben dar cuenta, por todos los paquetes, de cómo se halla la salud pública en los de su residencia y en los demás del mismo país que tengan relaciones de comercio con Venezuela, si faltan en ellos esos funcionarios. ${ }^{16}$

Esta recomendación se justificaba porque el propósito era obtener una amplia información sobre el estado sanitario de las naciones con las que se mantenían relaciones comerciales. Ante ese hecho, era necesario conocer los medios utilizados por otras naciones para combatir las epidemias y enfermedades, trastornadores del comercio exterior. Por consiguiente, los cónsules estaban obligados a recoger y remitir al gobierno "las publicaciones célebres que salgan sobre el cólera, muy en especial los métodos preventivos y los curativos aplicados con buen éxito". Más adelante agrega el documento que con frecuencia fueran comunicados al gobierno "los resultados producidos por las cuarentenas, que se impongan ya en tierra, ya a bordo de los buques, y si han llegado a suprimirse en alguna parte". ${ }^{17}$ Esto

16 Ídem.

17 Ídem. 
demuestra el interés del Ministerio para obtener, del funcionario consular, no sólo información sobre una determinada epidemia, sino también respecto a las experiencias preventivas y curativas adoptadas por otros países frente a enfermedades de gran riesgo, lo cual, en su conjunto, indica la importancia que el gobierno otorgaba a las acciones de tipo sanitario tendentes a proteger los factores humanos y materiales de los cuales dependía el comercio exterior venezolano.

\section{Previsiones en el país}

Este tipo de previsión era dictada por el gobierno nacional para ejecutarse en las regiones portuarias y sus alrededores. Su proyección espacial era limitada, concretándose a los puertos de La Guaira y Puerto Cabello, que eran las terminales más importantes. Las medidas sanitarias se referían especialmente al control de la fiebre amarilla, en razón de su carácter endémico. El cólera, aún siendo más devastador, no mereció la misma atención al no tener esa caracterización de endémico. Desde 1870 se incrementó el control sanitario y, para tal fin, se desarrollaron acciones como las analizadas anteriormente, que eran insuficientes. Esto puso en evidencia la necesidad de mejorar la coordinación sanitaria con los Consulados. Se pusieron en práctica una serie de mecanismos que culminaron en 1879 con un estudio científico elaborado por una comisión designada por el Tribunal de la Facultad Médica de Caracas, a solicitud del Ministerio de Relaciones Interiores. ${ }^{18}$ El estudio comprendía seis partes: la participación gubernamental, aislamiento y cuarentena, desinfección, desinfectantes utilizables, casos en que debieran usarse y recomendaciones personales para la profilaxis de la fiebre amarilla. A continuación se expone cada una de los apartados.

Partiendo de un principio equivocado, según el cual la fiebre amarilla era una enfermedad propagada desde el exterior, se solicitaba del gobierno su participación para impedirlo. En consecuencia, se exigía una mayor actividad de los cónsules venezolanos a través del envío de informes amplios y precisos de la situación sanitaria en los lugares de su residencia. Esos informes debían ser remitidos para su análisis a las Juntas de Sanidad y a la Facultad Médica, las cuales sugerirían las acciones ante cualquier even-

18 "Informe que presenta la Comisión nombrada por el Tribunal de la Facultad Médica de Caracas"; en Memoria del Ministerio de Relaciones Interiores, 1881, tomo I, Imprenta Nacional, Caracas, 1882, págs. 201 y ss. 
tualidad. También se solicitaba del gobierno una mayor preocupación para que las autoridades marítimas cumplieran de manera más efectiva sus labores de sanidad y de policía sanitaria, "no solamente para impedir la invasión, sino para prevenir el desarrollo en caso de que la importación de la enfermedad haya tenido efecto". ${ }^{19}$ Esas acciones debían complementarse con la firma de tratados internacionales y el cumplimiento de normas de higiene pública, establecidas por convenios internacionales. Se planteó también la necesidad de aprobar un Código de Salubridad Pública "que calcara la Facultad Médica de Caracas sobre los procedimientos en uso en todas las naciones, en especial en los Estados Unidos de América, y que sirva para todos los casos y todas las circunstancias". ${ }^{20}$

Los médicos autores del informe (C. González, M. M. Ponte, G. González y L. Rodríguez Hernández), cometían el error de confundir la situación sanitaria de Venezuela, propia de los trópicos, con la estadounidense, de naturaleza distinta y de características epidemiológicas diferentes. También se equivocaban al pensar que las leyes propuestas por ellos y sus medidas terapéuticas, eran una panacea para resolver los problemas sanitarios de Venezuela. Sin embargo, ese criterio dio como resultado la proposición de un Código extraño a la patología tropical y a la realidad sanitaria de Venezuela.

Un segundo aspecto del informe presentado por la Comisión Médica se refería a las medidas de aislamiento y cuarentena. Se recomendaba con carácter obligatorio la incomunicación de los barcos contaminados o sospechosos, debiendo cumplirse esa práctica en cada puerto como un oficio especializado y asesorado por médicos titulares. También los buques sometidos a cuarentena tenían que acatar estrictamente las recomendaciones de los médicos: movilización sólo con permiso médico, desinfección y aseo periódico, todo dirigido y supervisado por el médico de Sanidad. En el cumplimiento de todos los preceptos médico-sanitarios se responsabilizaba al capitán de la embarcación, quien por ninguna razón debía permitir el abandono individual o colectivo del barco:

...y si algún individuo abandonare el buque o si algún otro se presenta a bordo sin permiso escrito del médico de sanidad, probado que esto sea quedará aquel sujeto a los castigos que establecen las leyes...21

19 Ibídem, pág. 202.

20 Ídem.

21 Ibídem, pág. 203. 
En cuanto a la duración de la cuarentena, dependía de la naturaleza nosológica, la incubación y otras referencias circunstanciales. En todo caso, el médico decidiría al respecto.

Otra recomendación era la relacionada con la desinfección. Se insistía en la meticulosidad y se recomendaban "reglas concisas (...) tan sencillas y claras que puedan ponerse fácilmente en práctica por cualquier persona medianamente inteligente". ${ }^{22}$ Destacaban la importancia de seleccionar desinfectantes efectivos, fáciles de conseguir en estado puro y económico para el público. Se valoraba mucho que la gente dominara el arte de la desinfección. "Es importante -señalaban - que el pueblo conozca lo que es desinfección. Esta palabra — según se apunta - significa la destrucción de los venenos que ocasionan las enfermedades infectivas o contagiosas". ${ }^{23}$ Obsérvese aquí que la infección era atribuida a venenos, es decir, a pesar de existir preocupación por conocer la etiología de las infecciones, se desconocía el origen microbiano de las enfermedades, único recurso que podía explicar racionalmente la patología tropical venezolana.

Cuando se presentaban epidemias, las medidas mencionadas se cumplían con sorprendente eficacia en los puertos venezolanos y en las ciudades más importantes del país. Ninguna otra actividad, excepto la de combatir adversarios políticos, era observada con tanta rigurosidad como la de salvaguardar sanitariamente los lugares estratégicos de la nación. Esto se debía a que las enfermedades y epidemias potencialmente representaban un factor de inestabilidad, algo muy importante dentro de los esquemas políticos atrasados que caracterizaban a la Venezuela de esta época.

\section{Aplicación de providencias}

Como se ha dicho, el cumplimiento de los recursos legales y científicos en función del resguardo sanitario de los puertos, fue de estricta observación. Era muy difícil que una embarcación nacional o extranjera burlara el control de la policía portuaria, como también lo era que las autoridades respectivas no se enteraran de las vicisitudes sanitarias de los países de Europa y América, a través del telégrafo, la prensa y la información de viajeros y tripulantes. Cuando esto sucedía, se tomaban las medidas del caso

22 Ibídem, pág. 204.

23 Ídem. 
$\mathrm{y}$, aunque fueran remotas las posibilidades de un contagio epidémico, las acciones se implementaban como si se estuviera ante una emergencia.

La misma epidemia de cólera ocurrida en Europa en 1884 movilizó a las autoridades venezolanas. Por noticias consulares, el gobierno se enteró de un barco sospechoso de transportar cólera. Esta nave, que según los informes del cónsul no tenía previsto contacto alguno con puertos venezolanos, había atracado en la isla antillana de Santa Lucía, que mantenía vínculos comerciales y tráfico frecuente con esos puertos. Ante esa circunstancia, el gobierno ordenó, el 8 de agosto de ese año, que todos los buques procedentes de los lugares epidémicos fueran mantenidos "en rigurosa cuarentena... debiendo ésta llevarse a efecto a una distancia tal del puerto que evite el peligro de la comunicación con los buques detenidos". ${ }^{24}$ Con el cumplimiento de esa medida - cuyo hecho no era aislado - podemos comprobar la atención prestada al informe elaborado por la Facultad Médica de Caracas.

Para imponer la cuarentena no importaba que los buques portaran patentes limpias de navegación, porque las mismas, según el diagnóstico oficial, no bastaban:

...para evitar el riesgo (...) sino que es necesario también que la visita de sanidad se hace efectiva, inteligente y escrupulosamente, por la posibilidad que hay de que después de despachado el buque, se desarrolle en la travesía la epidemia por la incubación que de su germen pueda haber en cualquiera de los tripulantes. ${ }^{25}$

Sin lugar a dudas, las autoridades venezolanas contaban con una excelente asesoría científica en esta materia, que hacía extremar las medidas de seguridad. Según éstas, no bastaban las patentes limpias supervisadas por nuestros cónsules en el extranjero. Por las recomendaciones de la Facultad Médica (UCV), era necesario que la visita se realizara como si el documento de navegación no existiera. Aquí se ponía de manifiesto el temor gubernamental ante cualquier epidemia que, de presentarse, lo obligaría a cerrar sus puertos y dejar de percibir los respectivos impuestos fiscales al comercio exterior.

Medidas más extremas aún, fueron las tomadas a mediados de 1885 ante el cólera que azotó a casi toda la Península Ibérica. El 17 de julio de ese año, los cónsules de Venezuela informaban al Ministerio de Relaciones

24 "Resolución que previene a los administradores de Aduanas Marítimas, el cumplimiento de las medidas preventivas contra el cólera"; en Gaceta Oficial, N. ${ }^{\circ} 3.315,8$ de agosto de 1884 .

25 Ídem. 
Exteriores sobre la aparición de esa epidemia. "Miles de personas -agregaba el informe - abandonan precipitadamente la población de Madrid, y de mil ciento nueve casos, seiscientos veinte y ocho han sido fatales". ${ }^{26} \mathrm{El}$ mismo día los administradores de aduana de La Guaira, Puerto Cabello y Carúpano, recibieron telegramas en donde se les ordenaba "establecer con toda rigidez cuarentena en los buques procedentes de los puertos españoles, quedando dicha cuarentena subordinada a las disposiciones legales que rigen en la materia...". ${ }^{27}$

Ante el temor despertado por el cólera, el Ministerio de Relaciones Interiores escribió al de Exteriores y Hacienda y a todos los gobernadores, informándolos acerca de la epidemia y ordenándoles aplicar acciones de seguridad: cuarentena de barcos, nombramiento en cada Estado de Juntas de Sanidad y estricto cumplimiento de las previsiones. ${ }^{28}$

El ordenamiento es curioso en lo tocante al nombramiento de Juntas de Sanidad en aquellos lugares aislados, pues sólo se nombraban cuando sus pobladores directamente padecían epidemias. Probablemente su designación se debía - más que todo- al conocimiento de la existencia de naves contrabandistas, posibles portadoras de enfermedades que, escapando a las medidas de control, podrían arribar a las poblaciones costeras, marítimas y fluviales de Venezuela. Tal riesgo perjudicaba no sólo a quienes comerciaban directamente con esas embarcaciones, sino también a quienes vivían en poblaciones interiores que se abastecían de productos adquiridos por contrabando.

Lo mismo ocurría con esas poblaciones cuando se trasladaban con fines comerciales a puertos de islas antillanas de fácil acceso, en donde los controles sanitarios eran menos drásticos. ${ }^{29}$ De ese contacto podía derivarse el contagio y la consecuente propagación de la epidemia a territorio

26 "Circular a los ministros de Relaciones Exteriores y de Hacienda, gobernador del Distrito Federal y presidentes de los Estados, participándoles que el cólera asiático ha invadido algunos puntos de España; Caracas, 20 de julio de 1885" en Gaceta Oficial, N. ${ }^{\circ} 3.568$, julio 22 de 1885.

27 Ídem.

28 Ídem.

29 En 1874 el ministro de Hacienda se quejaba de tal comercio porque las regiones venezolanas que lo practicaban restringían por completo sus posibilidades de progreso, debido a la preferencia otorgada a mercancías extranjeras. Agregaba el ministro que gente de diferentes sectores sociales se trasladaban al puerto de la isla de Trinidad y llenaban "sus necesidades personales sin que la ley pueda impedírselo (...) el peonaje de toda esta cordillera (región oriental y llanos centrales), una vez que recibe sus salarios, se embarcan en las pequeñas embarcaciones que de continuo salen de este puerto (Barcelona) con dirección a aquel, y lo que aquí han ganado lo emplean en media docena de mudas de ropa que después introducen como de equipaje". Ver Memoria del Ministerio de Hacienda, 1874, Informe L, Imprenta Nacional, Caracas, 1875, pág. 112. 
venezolano. En esos casos, la función de las Juntas de Sanidad era importante porque permitía establecer cierto control sanitario en la zona, a la vez que facilitaba al gobierno disponer de información que lo facultaba para reprimir actividades de los políticos de oposición.

Las publicaciones en la prensa nacional e internacional, respecto al peligro de la extensión de epidemias desde el exterior a Venezuela, influían poderosamente en la implementación de medidas sanitarias. Así, el 1. ${ }^{\circ}$ de octubre de 1877, el Ministerio de Relaciones Interiores cursó comunicación al jefe civil del Distrito Federal y a las autoridades portuarias, para comunicarles que por informaciones periodísticas

...un barco napolitano llegado a Nueva York fue puesto en cuarentena por haber tenido durante su viaje ocho casos fatales de cólera; y aun cuando se crea improbable el contagio en aquel puerto norte-americano prevengo a usted la más escrupulosa vigilancia sobre todos los barcos que vengan de aquella procedencia. ${ }^{30}$

Con esas recomendaciones, el Gobierno nacional expresaba su preocupación y, al mismo tiempo, eliminaba cualquier posibilidad, por remota que fuera, de un contagio epidémico en nuestros puertos.

La amenaza de epidemias obligaba al Gobierno a improvisar medidas transitorias que debieron tener un carácter permanente para salvaguardar la salud de la población nacional en una forma constante. Con motivo del cólera español de 1885 fue propicia la oportunidad para que el Gobierno caraqueño se preocupara por la sanidad capitalina. El 22 de julio del mismo año dispuso:

...practicar una detenida inspección en todas las cloacas de la ciudad, con el fin de hacer que ellas se encuentren en el mejor estado de limpieza requerida. Los basureros públicos deberán ser desinfectados periódicamente (...) o bien destruidos por el fuego $(. .$.$) y realizar visitas a todos los establecimientos públicos (...) para informar-$ se de su estado de limpieza. ${ }^{31}$

Este era el "saldo positivo" de las epidemias de otros lugares del mundo en Venezuela; eran como una descarga eléctrica que despertaba a las

30 Telegrama. "A los Jefes Civiles de los Distritos ordenándoles la más estricta vigilancia sobre los barcos procedentes de lugares infectados por el cólera, para impedir su invasión a territorio de la República; Caracas, 1. ${ }^{\circ}$ de octubre de 1887"; en Gaceta Oficial, N. ${ }^{\circ} 4.115$, octubre 1. $^{\circ}$ de 1887.

31 "Resolución del gobierno del Distrito Federal disponiendo acciones sanitarias para evitar el cólera que se propaga en España; Caracas, 22 de julio de 1885”, en Gaceta Oficial, N. ${ }^{\circ}$ 3.570, julio 24 de 1885 . 
autoridades, obligándolas a reaccionar temporalmente frente al triste panorama vivido por nuestra sanidad nacional.

También en la ejecución de esas medidas se tomaban muy en cuenta aquellas recomendaciones que, en apariencia, no revestían mayor importancia. Una de ellas guardaba relación con el punto séptimo del documento del Ministerio de Relaciones Exteriores (mencionado anteriormente), respecto a medidas preventivas y terapéuticas experimentadas por otros países en la lucha contra el cólera. El 30 de julio de 1884 fue publicada en la Gaceta Oficial una nota del Ministro de Relaciones Exteriores, remisoria de otra del cónsul de Venezuela en San Nasario, sobre el tratamiento del cólera dado por un médico-científico de apellido Burg, quien había dedicado gran parte de su vida a la lucha contra esa enfermedad. Traducía el cónsul venezolano algunas conclusiones de Burg en las que señalaba al cobre y a las sales de éste, como agentes de prevención contra el flagelo. Se basaba en estudios realizados con obreros cupríferos, quienes no estaban afectados por el mal. Agregaba Burg que los casos fatales se debían al breve tiempo de trabajo en las minas de cobre, lo cual reducía la protección, precipitando la aparición de la enfermedad. Más adelante, las notas traducidas indicaban un tratamiento en base a soluciones de cobre, el cual era muy recomendado por el cónsul venezolano. ${ }^{32}$

Sobre las propiedades terapéuticas de ese metal en el tratamiento del cólera morbus, es muy poco lo que podríamos agregar. No obstante, resalta la seriedad con que eran tomadas las recomendaciones gubernamentales en todos aquellos detalles aparentemente sin importancia. Dado el peligro representado por una epidemia para la seguridad y estabilidad de las finanzas y la política de aquella época, no cabía otra cosa que la suma y búsqueda de todos los recursos habidos en función de las garantías políticas de la autocracia guzmancista.

Lo expuesto permite conocer el papel que desempeñaron las epidemias en la vida política y administrativa del país. Por una parte, obligaron al Gobierno a una mayor preocupación por el control de las enfermedades transmisibles, aunque las medidas tomadas muchas veces se limitaron a la circunscripción geográfica del territorio nacional en riesgo y a un lapso transitorio. Por otra, en ciertas ocasiones, las epidemias constituyeron oportunidad para que la oposición política utilizara esos periodos de cala-

32 "Nota del Ministro de Relaciones Exteriores al de Relaciones Interiores, relativa al cólera que se propaga en España”; en Gaceta Oficial, N. ${ }^{\circ} 3.307,30$ de julio de 1884. 
midad pública para provocar conflictos al gobierno. Pero, en todo caso, sea una u otra la circunstancia creada por las epidemias, siempre determinaron un beneficio para la salud pública porque dieron lugar a la realización de obras sanitarias, a la adopción de medidas preventivas o al enriquecimiento de los recursos terapéuticos para combatir aquellas enfermedades infecciosas.

Recibido el 26 de marzo de 2008 Aceptado el 4 de noviembre de 2008 